\title{
Analisa dan Implementasi Metode Zhang-Suen Dalam Pengerangkaan (Skeleton) Pada Citra Untuk Mengurangi Redundant
}

\author{
Annisa Rahayu \\ Program Studi Teknik Informatika, STMIK Budi Darma, Medan, Indonesia \\ Email: ${ }^{1}$ annisarahayu006@gmail.com
}

Submitted 13-01-2020; Accepted 09-02-2020; Published 15-02-2020

\begin{abstract}
Abstrak
Zhang-Suen merupakan suatu algoritma untuk proses pengerangkaan sebuah citra citra. Proses ini kerap diterapkan pada pra thinning digunakan misalnya tahap awal dalam proses pengenalan pola. Hal ini diimplementasikan dengan mengubah citra awal dengan pola binary menjadi representasi kerangka. Pada citra berbentuk garis, skeleton menunjukkan semua informasi dari objek aslinya.Komponenkomponen dari skeleton, yaitu posisi, orientasi, dan panjang segmen-segmen garis skeleton mewakili garis-garis yang membentuk image. Komponen-komponen ini mempermudah karakterisasi komponen-komponen dari image. Pada citra berbentuk garis, skeleton menunjukkan semua informasi dari objek aslinya. Komponen-komponen dari skeleton, yaitu posisi, orientasi, dan panjang segmen-segmen garis skeleton mewakili garis-garis yang membentuk image. Dalam proses pengerjaan skripsi ini perangkat lunak yang digunakan adalah MATLAB. MATLAB merupakan salah satu perangkat lunak dengan bahasa pemrograman tinggi. Adapun hasil akhir dari skripsi ini berupa objek yang dipertajam tepinya. Dalam pengerjaan skripsi menggunakan metode Zhang-Suen
\end{abstract}

Kata Kunci: Zhang-Suen, pengerangkaan skeleton, MATLAB.

\begin{abstract}
Zhang-Suen is an algorithm for the process of framing an image. This process is often applied to pre-thinning, for example, the initial stages in the pattern recognition process. This is implemented by changing the initial image with binary patterns to represent the framework. In a line-shaped image, the skeleton shows all the information from the original object. The components of the skeleton, namely the position, orientation, and length of the skeleton line segments represent the lines that form the image. These components make it easy to characterize the components of the image. In a line-shaped image, the skeleton shows all the information from the original object. The components of the skeleton, namely the position, orientation, and length of the skeleton line segments represent the lines that form the image. In the process of working on this thesis the software used is MATLAB. MATLAB is a software with a high programming language. The final results of this thesis are sharpened edges. In doing the thesis using the Zhang-Suen method
\end{abstract}

Keywords: Zhang-Suen, Skeleton Framing, MATLAB

\section{PENDAHULUAN}

Komputer sangat diperlukan sebagai sarana yang digunakan oleh setiap pemakai baik perorangan maupun instansi untuk mendapatkan informasi yang dibutuhkan dengan cara yang lebih mudah dan cepat, komputer digunakan untuk memenuhi segala kebutuhan dan membantu aktifitas dalam menyelesaikan permasalahan. Perbaikan kualitas citra adalah proses mendapatkan citra yang lebih mudah diinterpretasikan oleh mata manusia. Pada proses ini, ciri-ciri tertentu yang terdapat di dalam citra lebih diperjelas kemunculannya. Perbaikan citra bertujuan meningkatkan kualitas tampilan citra untuk pandangan manusia atau mengkonversi suatu citra agar memiliki format yang lebih baik sehingga citra tersebut menjadi lebih mudah diolah dengan mesin (komputer).

Citra atau Image merupakan istilah lain dari gambar, yang merupakan informasi berbentuk visual. Citra mempunyai karakteristik yang tidak dimiliki oleh data teks, yaitu citra kaya dengan informasi. Penggunaan citra digital semakin meningkat karena kelebihan-kelebihan yang dimiliki oleh citra digital tersebut, diantaranya adalah kemudahan dalam mendapatkan gambar, memperbanyak gambar, pengolahan gambar dan lain-lain. Akan tetapi tidak semua citra digital memiliki tampilan visual yang memuaskan mata manusia.

Dalam kecerdasan buatan dikenal suatu teknik pengenalan pola (pattern recognition). Pola yang dimaksud adalah matriks dua dimensi. Syarat yang harus dipenuhi sebelum melakukan proses pengenalan pola dengan melakukan pengerangkaan (skeleton) terhadap citra tersebut.

Pada citra berbentuk garis, skeleton menunjukkan semua informasi dari objek aslinya. Komponen-komponen dari skeleton, yaitu posisi, orientasi, dan panjang segmen-segmen garis skeleton mewakili garis-garis yang membentuk image. Komponen-komponen ini mempermudah karakterisasi komponen- komponen dari image tersebut. Misalnya panjang dari suatu bentuk dapat diperkirakan dengan memperhitungkan ujung-ujung dan titik terjauh pada skeleton. Thinning melakukan pengulangan (iteration), dimana piksel-piksel ini diseleksi dengan kriteria-kriteria tertentu untuk memutuskan atau membedakan antara piksel yang akan dihilangkan dan yang tidak dihilangkan. Terdapat cukup banyak thinning semuanya memiliki kelebihan dan kekurangan masing-masing.

Algoritma Thinning Zhang-Suen merupakan algoritma iteratif dan menghapus semua titik luar gambar kecuali ini menjadi kerangka. Metode ini digunakan untuk ekstraksi kerangka citra terdiri dari menghapus semua poin kontur gambar kecuali poin milik kerangka. Untuk mempertahankan kerangka citra maka T. Zhang dan C. Suen menyatakan bahwa proses ini akan membagi setiap iterasi menjadi dua-subiterasi [1].

Thinning merupakan suatu untuk proses pengerangkaan sebuah citra (image). Tujuannya adalah mengurangi bagian yang tidak perlu (redundant) sehingga dihasilkan informasi yang esensial saja. Pola penipisan harus tetap mempunyai bentuk yang menyerupai pola asalnya. Proses ini kerap diterapkan pada pra-thinning digunakan misalnya tahap awal dalam proses 
pengenalan pola. Hal ini diimplementasikan dengan mengubah citra awal dengan pola binary menjadi representasi kerangka (skeletal representation) image tersebut Dengan thinning, suatu fitur dari objek pada suatu citra dapat dikenali dan diekstrak sehingga dapat digunakan untuk pemrosesan lebih lanjut.

\section{METODE PENELITIAN}

\subsection{Citra}

Citra merupakan hasil keseluruhan dari suatu sistem perekaman data. Secara teoritis citra dapat dikelompokkan menjadi 2 (dua) macam, yaitu citra kontinu dan citra diskrit (citra digital). Citra kontinu dihasilkan dari sistem optik yang menerima sinyal analog. Contoh: mata manusia, kamera analog. Sedangkan citra digital dihasilkan melalui proses digitalisasi terhadap citra kontinu. Contoh: kamera digital, scanner[2].

\subsection{Pengenalan Pola}

Pola adalah entitas yang terdefinisi dan dapat didefinisikan melalui ciri-cirinya (feature). Ciri-ciri tersebut digunakan untuk membedakan suatu pola dengan pola yang lain. Pengenalan pola bertujuan untuk menentukan kelompok untuk kategori pola berdasarkan ciri-ciri yang dimiliki oleh pola tersebut.Dengan kata lain pengenalan pola membedakan object dengan object lain[2].

Ada 3 pendekatan yang digunakan dalam menerapkan pattern recognition (pengenalan pola), yaitu :

1. Statistik

Semakin banyak pola yang disimpan, maka sistem akan semakin cerdas. Salah satu contoh penerapannya banyak pada pola pengenalan iris scan. Kelemahannya : hanya bergantung pada data yang disimpan saja, tidak memiliki sesuatu struktur yang unik yang dapat menjadi kunci pengenalan pola.

2. Sintaks (rule)

Dengan rule / aturan maka sistem yang lebih terstruktur sehingga memiliki sesuatu ciri yang unik. Salah satu contoh penerapannya pada pola pengenalan sidik jari / fingerprint.

3. Jaringan Saraf Tiruan (JST)

Merupakan gabungan dari pendekatan statistik dan pendekatan sintaks. Dengan gabungan dari dua metode maka JST merupakan pengenalan pola yang lebih akurat. Salah satu contoh penerapannya pada pola pengenalan suatu citra JST merupakan suatu sistem yang dapat memproses informasi dengan meniru cara kerja jaringan saraf otak manusia.

\subsection{Algoritma Zhang-Suen}

Algoritma ini adalah algoritma untuk citra biner, dimana piksel background citra bernilai 0, dan piksel foreground (region) bernilai 1. Algoritma ini cocok digunakan untuk bentuk yang diperpanjang (elongated) dan dalam aplikasi OCR (Optical Character Recognition). Algoritma ini terdiri dari beberapa penelusuran, dimana setiap penelusurannya terdiri dari 2 langkah dasar yang diaplikasikan terhadap titik object (titik batas) region.Titik object ini dapat didefinisikan sebagai sembarang titik yang pikselnya bernilai 1 , dan memiliki paling sedikit 1 piksel dari 8-tetangganya yang bernilai $0[1]$.

Langkah pertama dari sebuah penelusuran adalah menandai semua titik object untuk dihapus, jika titik object tersebut memenuhi syarat-syarat berikut:

1. $2 \leq \mathrm{N}(\mathrm{P} 1) \leq 6$

2. $\mathrm{S}(\mathrm{P} 1)=1$

3. $\mathrm{P} 2 * \mathrm{P} 4 * \mathrm{P} 6=0$

4. $\mathrm{P} 4 * \mathrm{P} 6 * \mathrm{P} 8=0$

Keterangan :

a. jumlah dari tetangga titik object $\mathrm{P} 1$, yang pikselnya bernilai 1, yaitu: $\mathrm{N}(\mathrm{P} 1)=\mathrm{P} 2+\mathrm{P} 3+\mathrm{P} 4+\ldots+\mathrm{P} 9$

b. $\mathrm{S}(\mathrm{P} 1)$ adalah jumlah perpindahan nilai dari 0 (nol) ke 1 (satu) mulai dari P2, P3,.. P8, P9.

c. $\mathrm{P} 2 * \mathrm{P} 4 * \mathrm{P} 6=0$, memiliki arti $\mathrm{P} 2$ atau $\mathrm{P} 4$ atau $\mathrm{P} 6$ bernilai 0 (nol).

Dan pada langkah kedua, kondisi (a) dan (b) sama dengan langkah pertama, sedangkan kondisi (c) dan (d) diubah menjadi:

(c') $\mathrm{P} 2 * \mathrm{P} 4 * \mathrm{P} 8=0$;

(d') $\mathrm{P} 2 * \mathrm{P} 6 * \mathrm{P} 8=0$

\section{ANALISA DAN PEMBAHASAN}

Di dalam analisa citra, penulis akan menguraikan bagaimana pengerangkaan pada citra yang bertujuan pemisahan pada objek. Langkah selanjutnya dalam pengolahan citra adalah análisis citra (imageanalysis). Analisis citra bertujuan mengidentifikasi parameter-parameter yang diasosiasikan dengan ciri (feature) dari objek di dalam citra. Untuk selanjutnya parameter tersebut digunakan dalam menginterpretasi citra. Analisis citra pada dasarnya terdiri dari tiga tahapan : ekstraksi ciri (feature extraction), segmentasi dan klasifikasi. 
Adapun perbedaan antara citra yang berlebihan (redundant) dengan pengurangan citra yang memakai metode ZhangSuen sebagai berikut:
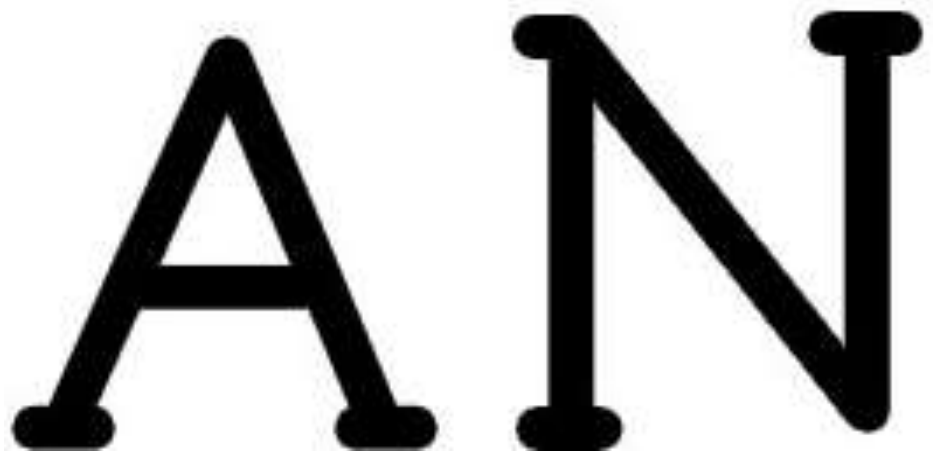

Gambar 1. Bentuk citra yang berlebihan (Redundant).
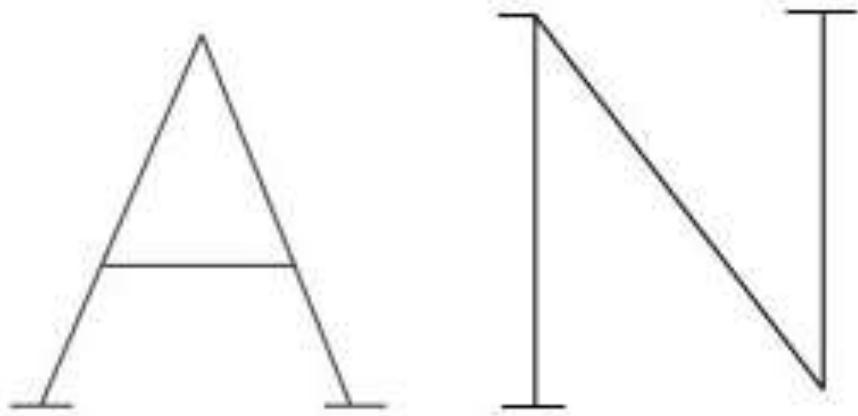

Gambar 2. Bentuk citra memakai metode Zhang-Suen.

Citra yang berlebihan (redundant) dan memakai metode Zhang-Suen terdapat perbedaan yaitu citra yang berlebihan (redundant) adalah memiliki ketebalan pada citra, oleh sebab itu citra yang berlebihan pada citra tersebut harus diekstrasi atau dikurangi agar pada citra tersebut menghasilkan suatu kerangka.Untuk menampilkan pengalamatan matriks untuk awal penelusuran dapat dilihat dari pada tabel 1.

Tabel 1. Bentuk Pengalamatan Citra

$\begin{array}{llll}\text { PX } & \text { PY } & \text { PZ } & \text { PA } \\ \text { P9 } & \text { P2 } & \text { P3 } & \text { PB } \\ \text { P8 } & \text { P1 } & \text { P4 } & \text { PC } \\ \text { P7 } & \text { P6 } & \text { P5 } & \text { PD }\end{array}$

Dalam penghapusan suatu piksel harus memenuhi suatu kriteria yang telah ditetapkan pada masing-masing algoritma. Setiap algoritma memiliki kondisi dan langkah-langkah cara kerja yang berbeda namun sama-sama menghasilkan suatu kerangka pola, jumlah penelusuran tergantung dari banyaknya kondisi yang memenuhi dari masing-masing algoritma. Bentuk penelusuran piksel dilakukan dengan 4 cara:

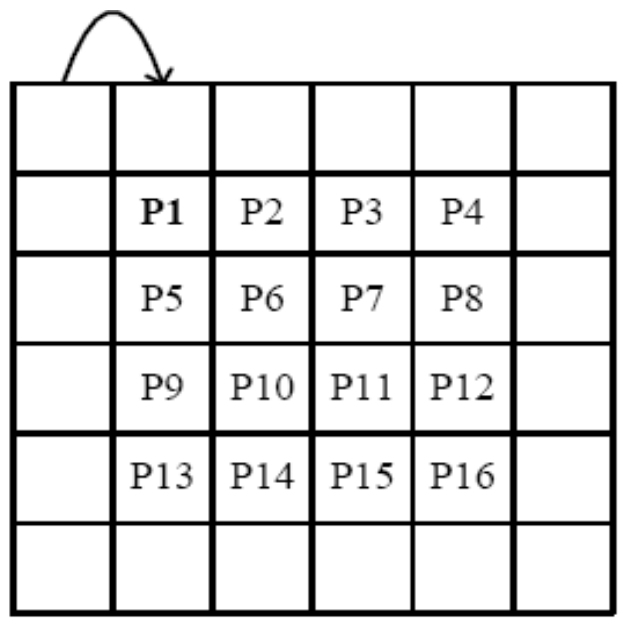


Gambar 3. Penelusuran objek dari kiri ke kanan dan dari atas ke bawah.

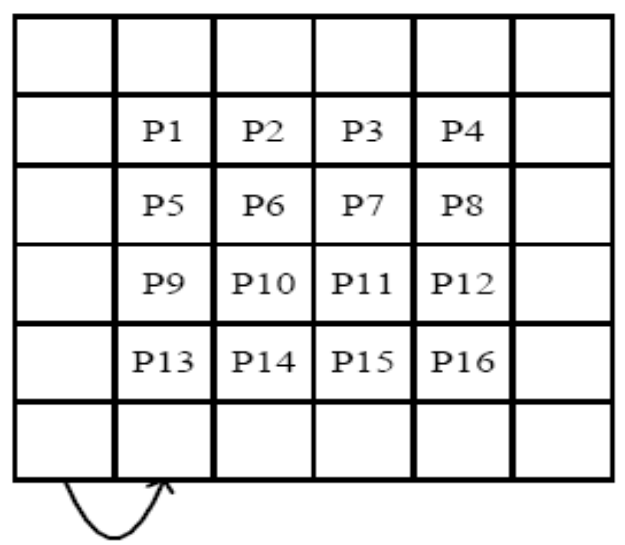

Gambar 4. Penelusuran objek dari bawah ke atas dan dari kiri ke kanan.

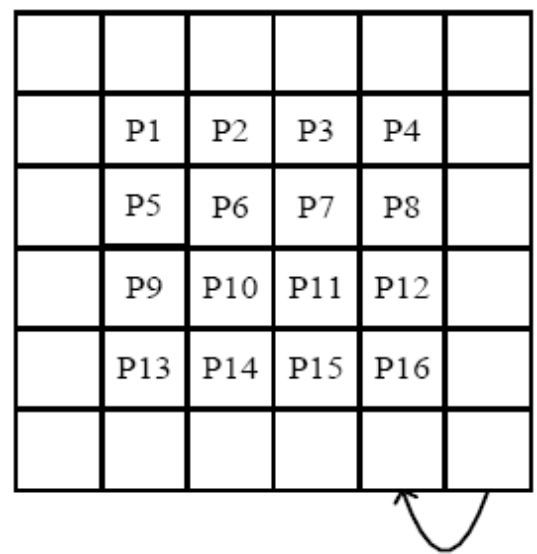

Gambar 5. Penelusuran objek dari dari kanan ke kiri dan dari bawah ke atas.

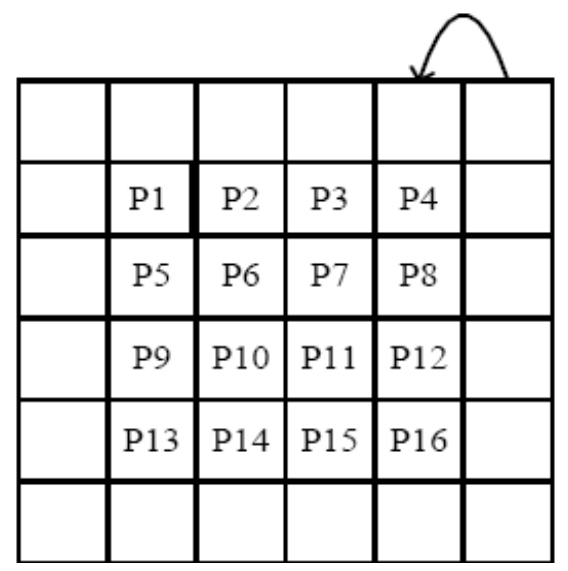

Gambar 6. Penelusuran objek dari atas ke bawah dan dari kanan ke kiri.

Penelusuran dimulai dari kiri kekanan dan dari atas kebawah. Penelusuran objek dimulai dari kolom 2 sampai 299 dan baris 2 sampai 199. Dengan perintah

For $\mathrm{b}=2$ To 199

For $\mathrm{k}=2$ To 299

Dimulai dari titik P1 dengan syarat dimana titik P1 harus bernilai 1 Citra Zhang-Suen $(\mathrm{k}, \mathrm{b})=1$

Tabel 2. Citra Awal Zhang-Suen

\begin{tabular}{lll}
\hline P1 & P2 & P3 \\
\hline P4 & P5 & P6 \\
P7 & P8 & P9 \\
\hline
\end{tabular}

Hasil Penelusuran Pertama (Langkah A dan B) Langkah A, harus memenuhi kondisi 1 sampai dengan 4 yaitu : 
a. $2 \leq \mathrm{N}(\mathrm{P} 1) \leq 6$

b. $\mathrm{S}(\mathrm{P} 1)=1$

c. $\mathrm{P} 2 * \mathrm{P} 4 * \mathrm{P} 6=0$

d. $\mathrm{P} 4 * \mathrm{P} 6 * \mathrm{P} 8=0$

Untuk Piksel P1 = $(\mathrm{P} 1)$

$\mathrm{N}(\mathrm{P} 1)=3$; TRUE

$\mathrm{S}(\mathrm{P} 1)=1$; TRUE

$\mathrm{P} 2 * \mathrm{P} 4 * \mathrm{P} 6=0 ;$ TRUE

$\mathrm{P} 4 * \mathrm{P} 6 * \mathrm{P} 8=0 ; \mathrm{TRUE}$

Kondisi dapat terpenuhi semua dengan nilai TRUE sehingga dapat disimpulkan bahwa P1 ditandai untuk dirubah menjadi background (nol).

Untuk Piksel P1 = (P2) pada gambar 3.7 :

$\mathrm{N}(\mathrm{P} 1)=5$; TRUE

$\mathrm{S}(\mathrm{P} 1)=1 ;$ TRUE

$\mathrm{P} 2 * \mathrm{P} 4 * \mathrm{P} 6=0 ;$ TRUE

$\mathrm{P} 4 * \mathrm{P} 6 * \mathrm{P} 8=0 ;$ FALSE

Kondisi tidak dapat bernilai TRUE semua untuk P1 $=(\mathrm{P} 2)$, hal ini di akibatkan karena kondisi P4* P6* P8 $=1$ bernilai FALSE, sehingga tidak ditandai atau pun dirubah pada langkah A dan B. Setelah melakukan cara yang sama untuk $\mathrm{P} 1=(\mathrm{P} 3), \mathrm{P} 1=(\mathrm{P} 4), \mathrm{P} 1=(\mathrm{P} 5), \mathrm{P} 1=(\mathrm{P} 6), \mathrm{P} 1=(\mathrm{P} 7), \mathrm{P} 1=(\mathrm{P} 8), \mathrm{P} 1=(\mathrm{P} 9)$,

Tabel 3. Hasil Proses Langkah 1 Algoritma Zhang-Suen

\begin{tabular}{ccc}
\hline 0 & P1 & 0 \\
\hline P2 & P3 & 0 \\
0 & 0 & 0 \\
\hline
\end{tabular}
menjadi:

Dan pada langkah kedua, kondisi (a) dan (b) sama dengan langkah pertama,sedangkan kondisi (c) dan (d) diubah

(c') $\mathrm{P} 2 * \mathrm{P} 4 * \mathrm{P} 8=0$

(d') $\mathrm{P} 2 * \mathrm{P} 6 * \mathrm{P} 8=0$

Untuk Piksel P1 = (P1) pada gambar 3.8

$\mathrm{N}(\mathrm{P} 1)=4 ;$ TRUE

$\mathrm{S}(\mathrm{P} 1)=1 ; \mathrm{TRUE}$

$\mathrm{P} 2 * \mathrm{P} 4 * \mathrm{P} 8=0 ;$ TRUE

$\mathrm{P} 2 * \mathrm{P} 6 * \mathrm{P} 8=0 ; \mathrm{TRUE}$

Kondisi dapat terpenuhi semua dengan nilai TRUE sehingga dapat disimpulkan bahwa P1 ditandai untuk di rubah menjadi background (nol). Setelah dilakukan cara yang sama terhadap $\mathrm{P} 1=(\mathrm{P} 2), \mathrm{P} 1=(\mathrm{P} 3)$ didapatkan citra setelah dilakukan proses thinning.

\section{IMPLEMENTASI}

Ada pun yang menjadi kebutuhan sistem adalah berdasarkan spesifikasi perangkat keras dan perangkat lunak standart, program ini dijalankan dengan menggunakan perangkat keras (Hardware) yang direkomendasikan adalah sebagai berikut :

1. Prosesor Intel(R) Dual Core(TM) CPU @ $2.0 \mathrm{GHz}$

2. RAM 2.0 GB

3. Harddisk $320 \mathrm{~GB}$, dengan freespace $2 \mathrm{~GB}$

4. Monitor dengan resolusi $1024 \times 768$ pixel

5. Keyboard dan Mouse

Ada pun tampilan dari penerapan metode Zhang-Suen untuk mengurangi redundant pada citra dapat dilihat dari tampilan berikut ini :

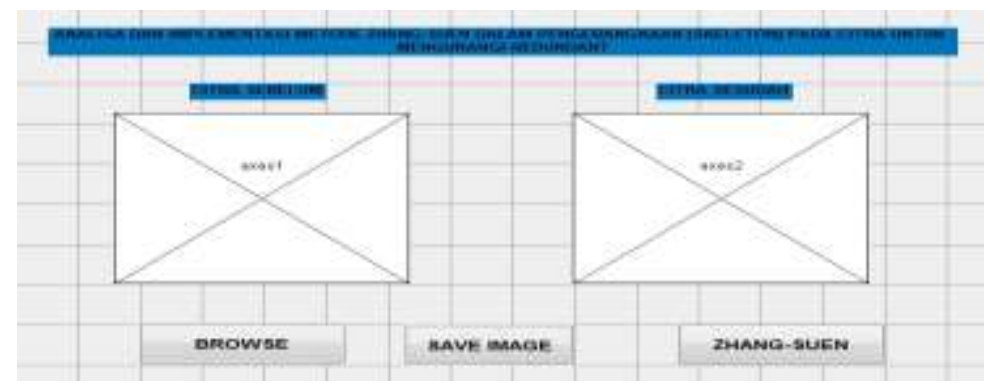

Gambar 6. Tampilan Program Utama 


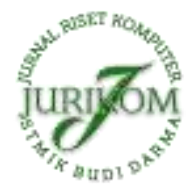

JURIKOM (Jurnal Riset Komputer), Vol. 7 No. 1, Februari 2020 e-ISSN 2715-7393 (Media Online), p-ISSN 2407-389X (Media Cetak) DOI 10.30865/jurikom.v7i1.1946 Hal 156-161

Berukut merupakan tampilan program untuk menginput gambar dari directory penyimpanan, gambar di input berfungsi untuk memperbaiki redundant citra tersebut.

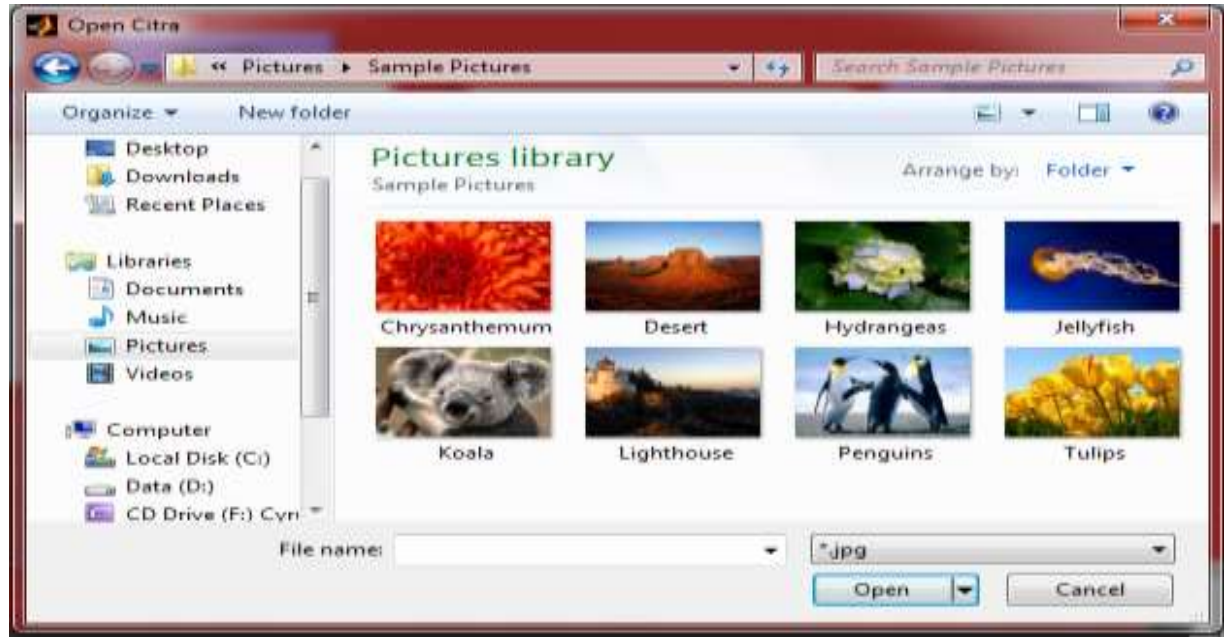

Gambar 7. Tampilan Cari Citra

Setelah tombol browser di klik maka akan masuk ke directory penyimpanan citra, setelah citra tersebut ditemukan maka langkah selanjutnya yang dilakukan oleh user adalah klik open maka citra akan muncul.

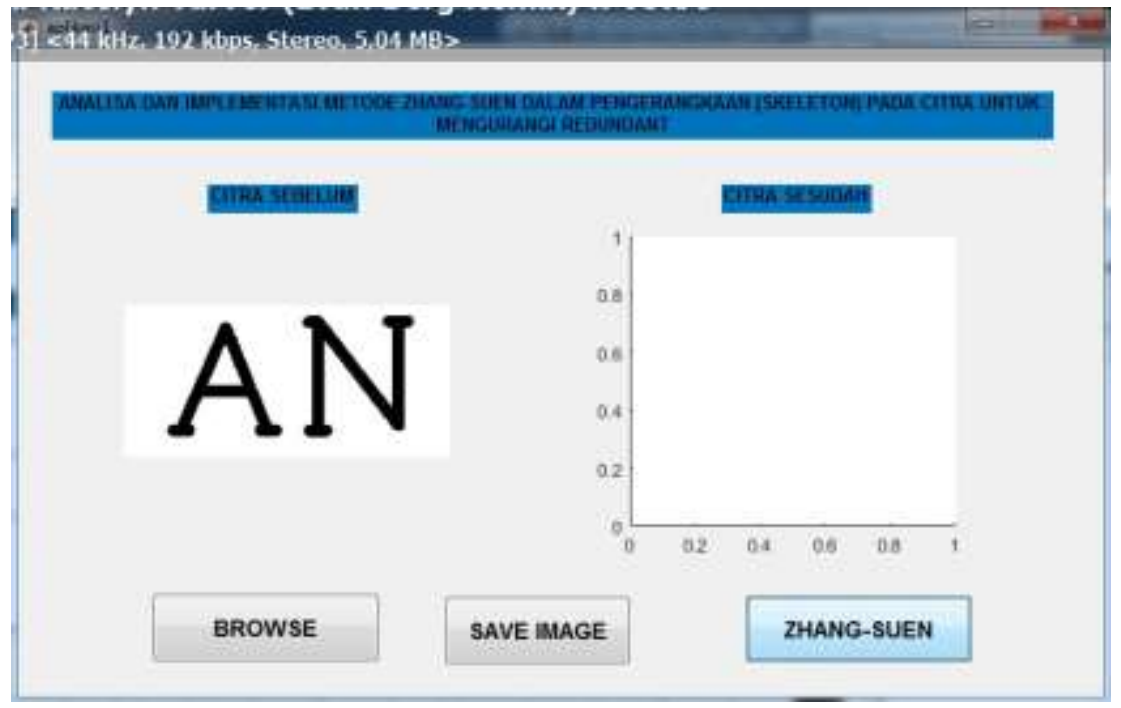

Gambar 8. Tampilan Input Citra

Setelah citra di input maka akan muncul citra yang berkerangka dan langkah selanjutnya dengan mengurangi redundant pada citra tersebut.

\section{KESIMPULAN}

Berdasarkan analisa dan pembahasan yang dilakukan, maka dapat disimpulkan sebagai berikut :

1. Memperbaiki pengerangkaan skeleton pada citra agar lebih bagus.

2. Menerapkan metode Zhang-Suen untuk pengerangkaan skeleton pada citra dengan menggunakan perhitunganperhitungan yang sesuai dengan tahapan pada metode Zhang-Suen.

3. Perancangan aplikasi dengan menggunakan software Matlab sangat memudahkan untuk mengolah data citra.

\section{REFERENCES}

[1] Fakhrina, dkk, 2016, "Thinning Zhang Shuen Dan Stentiford Untuk Menentukan Ekstraksi Ciri (Minitiae) Sebagai Indentifikasi Pola Sidik Jari Whorl Dan Loop”, Jurnal Teknik Elektro, Vol. 15 No. 2.

[2] Putra, Darma, "Pengolahan Citra Digital", 2010, Penerbit Andi, Yogyakarta.

[3] Sitorus, S, dkk, "Pengolahan Citra Digital, 2006, Penerbit Andi, Yogyakarta.

[4] S, Riyanto, dkk, 2005, "Step by Step Pengolahan Citra Digital” hal ; 23, Penerbit Andi, Yogyakarta.

[5] A.S. Rosa dan Shalahuddin. M, 2013, "Rekayasa Perangkat Lunak Terstruktur", Andi, Yogyakarta.

[6] Nugroho, Adi, 2009, “Rekayasa Perangkat Lunak Menggunakan UML dan Java” Penerbit Andi, Yogyakarta. 